\title{
Impact of headache in Europe: a review for the Eurolight project
}

\author{
Lars Jacob Stovner · Colette Andrée • \\ On behalf of the Eurolight Steering Committee
}

Received: 26 February 2008/Accepted: 1 April 2008/Published online: 17 April 2008

(c) Springer-Verlag 2008

\begin{abstract}
A recent health economic survey in Europe has suggested that migraine is the costliest among the neurological disorders. According to many studies, migraine and other disorders lead to widespread suffering, reduction of quality of life, and marked impairment of participation, both in work and social activities. The present literature survey was made in order to summarize what is known on the subject, as a preparation for a EU-supported study to assess the impact in several EU countries with similar methodology and the same research instrument. Previous studies have yielded relatively reliable data only for migraine, whereas the impact of tension-type headache is virtually unknown or only very incompletely known for most dimensions of headache impact. Some data do suggest, however, that this headache may be as important from a health economic and a public health perspective as migraine. In future studies it is important to get populationbased data from various countries relevant for estimation of indirect (mostly absenteeism from work and reduced working efficiency when having headache) and direct costs
\end{abstract}

\author{
L. J. Stovner $(\bowtie)$ \\ Norwegian National Headache Centre, \\ Department of Neuroscience, Norwegian University of Science \\ and Technology, Trondheim, Norway \\ e-mail: lars.stovner@ntnu.no \\ L. J. Stovner \\ St Olavs Hospital, Trondheim, Norway \\ C. Andrée \\ CRP Santé, Luxembourg, Switzerland \\ C. Andrée \\ Department of Pharmaceutical Sciences, \\ University of Basel, Basel, Switzerland
}

(related to medication, consultations, investigations and hospitalisations). Also, the impact on ability to get education and participate in the workforce is very relevant, as is the impact on love life and family planning. The quality of life of headache patients should be measured by validated instruments. To get a complete picture, one should also ask about the effect on the life of partners and children, and on the possible impact even when headache-free (e.g. fear of the next attack).

Keywords Burden · Disability · Eurolight · Headache . Impact · Migraine

\section{Introduction}

For a just and rational distribution of means to health-care services and health-related research, reliable data on the individual and societal impact of different disorders are crucial. In recent years several initiatives have been launched to raise the awareness that headache is not only a nuisance for some individuals, but also that it entails widespread suffering and loss of opportunities for patients and their families, and large cost for the society. The recently published report on the prevalence and burden of headache [1] is a premise for the campaign "Lifting the burden: The Global Campaign to reduce the burden of headache"[2]. In Europe, much data on both the economic costs of migraine have been collected and presented in connection with the "Cost of Brain Disorders in Europe" project [3], in which migraine is treated along with many of the other (neurological and psychiatric) "brain disorders". The Eurolight project (http://www.eurolight-online.eu) is an initiative supported by the EC Public Health Excecutive Agency launched in May 2007. Its objectives are to 
bring together the relevant medical, scientific and lay organizations, and to gather updated reliable comparable information regarding migraine, tension-type and chronic headache. It will be the first data collection on headaches at EU level focusing on a holistic, patient-driven and scientifically validated approach, aiming to fill in the main holes in our knowledge by performing comparable studies on headache prevalence and its impact in selected European countries (Austria, France, Germany, Italy, Lithuania, the Netherlands, Spain, UK, Ireland, Luxembourg). A pilot study has already been performed in Luxembourg. The present review of the existing literature on both economic and non-economic impact was performed as a part of the Eurolight project, to assess the current state of knowledge, and to build up a questionnaire to measure all the most relevant aspects of headache impact. This study presents the results of this review and a suggestion of the main dimensions that ought to be covered in the headache impact tool to be used in the Eurolight study.

\section{Economic impact of headache}

Headache may have considerable economic consequences, both for the patient and for the society as a whole. There are more studies about the societal costs than about the individual economic losses of the patients.

Relation to socioeconomic status, education and employment

In a large Norwegian study (the HUNT study), both migraine and headache in general was associated with low socioeconomic status [4], which has also been found in North America [5, 6] but not in some smaller European studies [7-11]. The question whether this is a consequence or a cause of headache is not satisfactorily answered, but in one Swedish study, half of the patients reported a negative influence of migraine on their ability to pursue studies and one third a negative influence on their finances [9]. In a US study it was found that headache patients have somewhat reduced labour force participation [12], but employment status has not been found to be related to headache in some European studies [7, 13].

Absenteeism from work

In two relatively old studies, one from Finland in 1979 [14] and one from San Marino in 1986 [15], 7\% of working individuals had been absent from work in the previous year due headache. In a Danish study of 1992 [16], it was found that $43 \%$ of migraineurs (5\% of the population) and $12 \%$ of TTH patients (9\% of the population) had been absent from work during the previous year due to headache, i.e. a total of $14 \%$ of the population. In a Swedish study of 2004 [9], it was found that $65 \%$ of migraineurs reported some degree of absence from either school or work during the previous year. These data are, however, of relatively limited interest from an economical viewpoint as they do not indicate the number of days that the headache sufferers are away from work.

The number of days with work absence due to headache is relatively consistent across studies from different countries. In some previous studies it has varied between 2 and 6 days per year among headache patients in general [17], and between 1.5 and 4.2 days per year in migraineurs [9]. A study among migraineurs in Sweden revealed that $35 \%$ were never absent from work due to migraine, and 54\% were absent 1-2 days per year [9]. Compared to headache-free individuals, migraine patients in the HUNT study from Norway lost on average 4.4 workdays per year, and persons with non-migrainous headache lost 2.5 workdays per year [18]. In the Danish study from Copenhagen [16], the TTH patients who had been absent seem to have been as much or more absent from work than the migraine patients, and the number of workdays lost due to migraine was 270 and to TTH 820 per 1,000 persons per year, i.e. a total of 1,090 days. In a study from England in 2003 [13], 15\% had been absent from work or had reduced ability to work due to headaches in the previous 3 months. Per year, headache accounted for 1,327 missed and 5,213 reduced ability days per 1,000 workers per year, representing 0.5 and $2.0 \%$ of all working days in the adult population, irrespective of headache status. This study did not relate absenteeism to different headache diagnoses. In an English study of 2003, an estimated 5.7 workdays per year was missed by migraineurs working or attending school [8]. This seems to be higher than in France where a diary-based registration of absenteeism published in 1999 showed that migraineurs were away from work 2.18 days per year due to headache [19].

\section{Effectiveness when working with headache}

Working with migraine results in a $35 \%$ productivity loss on average according to some European studies [20]. This figure is, however, largely based on migraineurs' selfreport, which may give a too high estimate according to a recent US study from a workplace[21]. In this study, it was found that the working ability assessed by self-report was much lower than the objectively measured working efficiency ( 20 vs. $8 \%$ ). The relatively small decline in working ability led the authors to conclude that workers with even relatively severe headache find creative ways to cope with the pain and maintain standards. 
Health economic studies

For the headache part of the "Cost of Brain Disorders in Europe" project, a literature search for studies containing cost data for migraine and other headaches identified eight European studies evaluating the direct or indirect costs of migraine from a societal perspective [20], from France [22, 23], Germany [24], The Netherlands [25], Spain [26], Sweden [27] and the UK [28, 29]. No studies analysing the cost of TTH or other non-migraineous headaches were found. There were large variations in costs across the six European countries where data were available, ranging from around $€ 100$ per patient per year in Sweden to nearly $€ 900$ in Germany. These variations are probably mostly due to different methodologies and differences in the year when the studies were conducted. An important finding was that the vast majority of total costs, between 72 and $98 \%$, was indirect costs, due to lost productivity, either in the form of work absence or reduced efficiency levels when working with migraine. Women tended to lose more workdays than men, but indirect costs were similar due to lower salaries and labour force participation amongst women. The direct costs, related to consultation, diagnostic investigations, treatments, and hospital admissions accounted for less than $30 \%$ of total costs in most studies.

The cost estimate for migraine in the European report was based on an average of the most representative cost estimates, from the UK, Germany and France. An average annual cost of $€ 585$ per migraine patient was estimated for these Western European countries. The 1-year prevalence of migraine was $14 \%$ among adults in Europe according to the review of epidemiological studies [1], i.e. 41 million adult Europeans with active migraine. Per patient migraine was the least costly disorder among the brain disorders. However, due to the high prevalence, the total cost of migraine was estimated to be $€ 27$ billion for whole Europe in 2004, which was the highest cost among the purely neurological disorders. Many of the psychiatric afflictions were even more costly according to this review. It is, however, likely that the available cost data in Europe would tend to underestimate the actual costs of headache, mainly because no cost data existed on the most common headache type (TTH), but also because children and adolescents were not considered, and because cost connected with more expensive medication (triptans) were not included, since most cost studies were performed before this class of drugs was introduced.

In a separate paper summarizing the prevalence and cost data for headache in Europe [30] a more speculative estimate for the cost of headache, rather than migraine alone, was derived by using the results of the Danish [31] and British [32] population-based studies which demonstrated that around 1,100-1,300 days per 1,000 workers were missed due to headache each year. The British study also suggested that the number of days with reduced efficacy was around four times higher than the number of days missed. Assuming a reduced efficiency of $35 \%$ when working with headache, and that the direct costs of headache constitute the same proportion of the total costs as for migraine, the average total cost per headache patient was estimated to be roughly $€ 420$ per year (of which $€ 390$ would be due to indirect costs and $€ 30$ due to direct medical costs). Since headache in general was found to affect nearly $50 \%$ of Europeans, this estimate, if true, would make headache a much more costly disorder than migraine alone.

It is of interest to compare the European cost study [3] with more recent cost studies in some individual European countries. In one study from Spain [33] the annual costs of migraine was only about $50 \%$ of the sum given in the European Cost study for the same country. The difference may partly be explained by somewhat lower prevalence figures (12 vs. 14\%) for migraine used in the Spanish study, but the main difference may be that this study did not employ a bottom-up design, but used published statistics and data to estimate resource use and productivity losses, which may have led to an underestimation of some costs. A recent study from France [34], restricted to the direct costs in 1999, found that these costs were at least twice as high $(€ 128)$ as in the European migraine cost study $(<€ 60)$. This study included both "strict" migraine (IHS 1.1 and 1.2) and "migraineous disorder" (IHS 1.7, corresponding to 1.6 in ICHD-2), which together affected $17 \%$ of the population. For the whole country the direct costs amounted to more than 1 billion $€$, which was $0.068 \%$ of the gross national product. Non-migraineous episodic headache, affecting $9.2 \%$ of the population, entailed a considerably lower cost of $€ 28$.

It may also be of interest to compare the European studies with one US study using a quite different methodology to assess direct costs. In this study, all types of medical care costs (not only those related to headache) were derived from the claims records of a large health plan, whereas diagnostic status (migraine or not) and comorbid and demographic status was ascertained using a telephone interview among members of the health plan [35]. Migraineurs incurred on average $\$ 700$ more per year in total medical care costs than the controls. Interestingly, this statistically significant difference disappeared when psychiatric comorbidity variables (anxiety and depression) were entered into the model. The much higher costs per patient reflected in this study than in the French study [34] and Spanish study [33] may therefore at least partly be due to the differences in cost assessment methodology, indicating that the direct costs specifically related to migraine and not to comorbid disorders are most reliably assessed by 
a direct method, questioning patients about use of healthcare resources.

Medication for headache constitutes an important part of the direct costs. In France in year 2000, the most frequently used acute medications for migraine were paracetamol, salicylates and NSAIDs. Triptans were used by $8 \%$ of migraineurs, and prophylactic treatment was used by $6 \%$ [36]. In Denmark 26\% of migraineurs had used triptans in 2001 , but less than $5 \%$ of those with pure migraine had used prophylactic medication [37].

\section{Non-economic impact}

From a purely humanitarian perspective, but also from a public health perspective, the pain, suffering and disability caused by headaches are as important as the economic consequences. In a study performed in young women in nine Western European countries, $86 \%$ of migraineurs stated that their life would have been better if they did not suffer form migraine [38]. A German study showed that, on average, patients with migraine or TTH had around 1 month every year affected by headaches [10]. The main burden of headache is carried by a minority of sufferers, and a Swedish study has shown that $27 \%$ of migraine patients had $68 \%$ of all attacks [9]. Three to $4 \%$ of the European population have headache half of the days or more per month [1].

\section{Disability}

It has been calculated that in the US, 300,000 persons stay in bed each day (24 h) due to headaches [39]. A Swedish study has shown that the disability is not only related to the attacks since many migraine patients report an impairment also between attacks [40]. Nine \% of patients report that they have some residual disability since they do not recover completely between attacks, and in addition, many patients live in a constant worry about the next attack [9, 38].

In some studies, the level of disability due to migraine has been evaluated with the Migraine Disability Assessment Scale (MIDAS). With this instrument, days with work absence (job or household chores), days with $\geq 50 \%$ reduction in productivity, and days with inability to participate in social activities are counted during a 3-month period. In France, among those with active migraine, $22 \%$ ( $1.5 \%$ of the whole population) had grades III or IV disability (moderate or severe disability, indicating 11 days or more during the last 3 months' period when headache affected work/household chores $50 \%$ or more, or leisure activities) [36]. MIDAS III or IV were about twice as common among migraineurs in one US study (54\%) [41], as it was in the multinational Latin American study (50\%) [42]. Among patients with headache in general (both migraine and non-migraineous headache, comprising $70 \%$ of the study population), $10.3 \%$ (7.2\% of the population) had MIDAS grade III or IV disability [13]. Comparing the percentage of the general population in France with MIDAS disability grade III-IV due to migraine (1.5\%) [36], with the percentage of population in England with same disability due to headache in general $(7.2 \%)$ [13], it seems that nonmigraineous headache causes more disability on a population than does migraine. The headache-attributed lost time (HALT) index is a close derivative of MIDAS (http://www. liftingtheburden.org/ $\rightarrow$ Resources $\rightarrow$ Burden measure) to be used for headache burden studies, which will be conducted by the Lifting The Burden Campaign [43].

According to the World Health Organisation (WHO), the preferred measure of disease burden is "Disability Adjusted Life Years" (DALYs), which is a sum of the years of life lost (YLL) and the years lived with disability (YLDs). The YLDs are determined by the incidence and duration of the disorder, and by a disability weight ranging between 0 and 1 [44]. Although migraine entails no increased mortality (i.e. YLL $=0$ ), it ranked the 19th among the leading causes of DALYs among women aged between 15-44 years, and with regard to YLDs, it was 19th for both sexes, and the 12th for women, irrespective of age. Using the WHO data for a calculation of the burden of "brain disorders" (i.e. the psychiatric and neurological disorders) in Europe, the weight of migraine was lower than that of the major psychiatric disorders, dementias, stroke and injuries, but higher than that of epilepsy, multiple sclerosis and Parkinson's disease[45].

In a recent report on the global prevalence and burden of headache disorders, the burden of migraine and TTH were measured in a similar way as the DALYs by combining data on prevalence, mean number and duration of headache attacks, and headache intensity, from studies containing such information. For the world as a whole, it was demonstrated that TTH resulted in a higher population burden (approximately $55 \%$ of total burden) than migraine (45\%). The data for Europe indicated an even higher burden due to TTH compared to migraine [1]. If one uses the European data from this study it can be calculated that the hours with migraine headache would add up to between 34 and $100 \mathrm{~h}$ per year, if distributed on each adult individual in the population. The data on TTH are too scarce to use for similar calculations.

\section{Studies using validated QoL-instruments}

The SF-36 is a validated instrument to measure quality of life (QoL), containing eight dimensions. One US study 
[46], recruiting migraine patients from a medication trial, demonstrated that migraineurs had lower QoL than the general US population, most marked for bodily pain, physical role limitations and social functioning.

A Dutch population-based study found that migraine had a negative influence on all a dimensions compared to controls. The negative influence on QoL was larger than that of e.g. asthma, and it increased with increasing headache frequency [47]. Two population-based studies from Spain among chronic daily headache sufferers showed a marked negative influence, most marked for those with medication overuse, but similar for those with a headache of a migraine or a tension type [48]. One of these showed that the headache frequency may have a greater impact than headache intensity on QoL [48], and the other that chronic headache with medication overuse was associated with a decrease in all QoL aspects studied with SF-36, most marked for physical role and bodily pain [49]. A study from UK showed that migraineurs with high or moderate disability had a marked reduction on all dimensions on the SF-36 [50]. One Swedish study compared SF-36 results in the two sexes and in participants with different pain conditions. There was a gender difference for headache, which in men influenced physical function, physical role and bodily pain most, and in women vitality, social functioning, emotional functioning and mental health [51]. In a French study, migraineurs had significantly lower scores than headache-free controls on all SF-36 dimensions, and lower scores on the pain dimension than those with other headaches or with TTH [52].

One study comparing migraineurs in the US and the UK used a shorter QoL instrument, the SF-12, which contains a physical and a mental component [53]. In both countries, migraineurs had lower scores than controls on both components also after adjusting for socioeconomic status and for depression. However, in those with both migraine and depression, the QoL was significantly reduced in comparison to those who were not depressed.

In another French study, using a disease-specific QoL instrument called QVM, the QoL was found to be lowest among those with chronic headache, intermediate among migraineurs and highest among subjects with other forms of episodic headache [54].

The total burden of headache patients may not only be related to the headache per se, but also to comorbid conditions. European population-based studies have demonstrated that depression and/or anxiety occur two to three times more often among migraineurs than in the general population $[55,56]$. Depression adds to the reduction in QoL in migraine [53]. This comorbidity may be as important for non-migrainous headache [57], but it is not known how this comorbidity influences the QoL in other headaches. In addition, it has been found that headache is also comorbid with other bodily pain, both in Finnish children [58] and Norwegian adults [59].

\section{Family impact of migraine}

Migraine also affects the patients' spouses and children. In a population-based Swedish study [9], the percentage of migraine sufferers who reported a negative impact of migraine was $76 \%$ for attendance to work, $67 \%$ for family situation, $59 \%$ for leisure time, $48 \%$ for pursuing studies, $46 \%$ for sexual life, $37 \%$ for their social position, $31 \%$ for love, $30 \%$ for their financial situation, $27 \%$ for making a career, and $11 \%$ for making friends.

One study has measured the impact on the family in two population samples of similar size in US and UK [60]. The impact was very similar in both countries. More than $60 \%$ of patients reported a marked impact on the ability to do household chores because of their migraine during the past 3 months, and it was markedly reduced also in $20 \%$ of the patients' partners. Almost $46 \%$ of patients, and $24 \%$ of partners had missed days of family or social activities due to the proband's migraine, and $16 \%$ of patients and $12 \%$ of partners had avoided making plans for family or social activities due to the proband's migraine. As to the impact on the children of patients, more than $60 \%$ stated that it had a moderate to marked influence on the relation with their children, $40 \%$ stated that they would have been a better guardian or parent without migraine, more than $10 \%$ stated that their children had missed school, and $10 \%$ that their children had been late to school because of their headache. Forty-six percent of patients stated that they would have been better partners without headaches, and 5\% stated that they had had fewer children because of headache, $0.4 \%$ that they had avoided having children, and $15 \%$ that they had avoided oral contraception. Compared with a control group, the partners of migraine patients were significantly more dissatisfied with the demands, responsibility and duties placed upon them, and with their ability to perform.

\section{Conclusions}

Health economic studies have documented that the costs of headache disorders are huge; the costs only for migraine amounting to $€ 27$ billion in the EU countries, and the cost for other headaches are probably as large. However, better population-based cost studies are needed to assess the cost involved with TTH. Headache sufferers tend to have lower income and education, and more of them may be 
Table 1 The main domains that should be covered in headache burden studies

\begin{tabular}{ll}
\hline $\begin{array}{l}\text { Economic burden } \\
\text { Direct cost }\end{array}$ & Medication, consultation, investigations, hospitalisations \\
Indirect costs & Workdays lost \\
& Decreased effectiveness when working with headache \\
& Lost career and education opportunities \\
Non-economic burden & MIDAS or HALT \\
Disability & Time with disability: Headache frequency x duration x \\
& intensity/disability \\
Residual disability and fear of next attack \\
Quality of Life & SF 36, SF 12, WHOQual etc \\
Family impact & Impact on the life of partner and/or children \\
& Impact on marriage and love life \\
Impact on family planning and/or contraception & Various scales to measure anxiety and/or depression as consequent or \\
comorbid disorders (e.g. HADS)
\end{tabular}

unemployed, but it is still uncertain whether this is true for most European countries, and also whether it may be a cause of or an effect of headache. It is also amply documented that migraine confers a high degree of disability with more forced absence from work and leisure activities, and migraineurs also have a measurably reduced quality of life. In addition, there is a marked impact on family life, and headaches also put considerable strains on partners and children. A minority of headache sufferers chose to have fewer children than they would have had if they had not had headaches.

Based on the present review we have identified some main domains, summarized in the Table 1, that should be covered in order to capture as much as possible of the headache burden. The investigations should be performed in population-based samples, and to assess the whole burden, it is particularly important that not only migraine is included but also TTH and the chronic headaches. Different studies show marked variations between countries, both with regard to prevalence and burden of headache. At present it is not possible to determine with certainty whether these differences are real or due to variations in methodology. This highlights the need to study several countries with the same methodology and instrument, which will be done in the ongoing studies of the Eurolight. If further research shows that there are real and important differences between various countries and regions, investigations to determine the causes of such differences may elucidate ways to lower the burden of headache in a population. In any case, we believe that the Eurolight studies will provide the evidence needed to let headache disorders get the resources for treatment and research that they deserve according to the burden they place on people in Europe.
Conflict of interest The first author has received honoraria, travel grants or research grants from GSK, Pfizer, Almirall, Nycomed, Desitin Pharma, MSD, Serono, AstraZeneca.

\section{References}

1. Stovner L, Hagen K, Jensen R, Katsarava Z, Lipton R, Scher A, Steiner T, Zwart JA (2007) The global burden of headache: a documentation of headache prevalence and disability worldwide. Cephalalgia 27:193-210

2. Steiner TJ (2004) Lifting the burden: the global campaign against headache. Lancet Neurol 3:204-205

3. Andlin-Sobocki P, Jönsson B, Wittchen HU, Olesen J (2005) Cost of disorders of the brain in Europe. Eur J Neurol 12:1-27

4. Hagen K, Vatten L, Stovner LJ, Zwart JA, Krokstad S, Bovim G (2002) Low socio-economic status is associated with increased risk of frequent headache: a prospective study of 22718 adults in Norway. Cephalalgia 22:672-679

5. Stewart WF, Lipton RB, Celentano DD, Reed ML (1992) Prevalence of migraine headache in the United States. Relation to age, income, race, and other sociodemographic factors. JAMA 267:64-69

6. Breslau N, Davis GC, Andreski P (1991) Migraine, psychiatric disorders, and suicide attempts: an epidemiologic study of young adults. Psychiatry Res 37:11-23

7. Rasmussen BK (1992) Migraine and tension-type headache in a general population: psychosocial factors. Int $\mathrm{J}$ Epidemiol 12:1138-1143

8. Steiner TJ, Scher AI, Stewart WF, Kolodner K, Liberman J, Lipton RB (2003) The prevalence and disability burden of adult migraine in England and their relationships to age, gender and ethnicity. Cephalalgia 23:519-527

9. Linde M, Dahlöf C (2004) Attitudes and burden of disease among self-considered migraineurs-a nation-wide population-based survey in Sweden. Cephalalgia 24:455-465

10. Gobel H, Petersen-Braun M, Soyka D (1994) The epidemiology of headache in Germany: a nationwide survey of a representative sample on the basis of the headache classification of the International Headache Society. Cephalalgia 14:97-106 
11. Launer LJ, Terwindt GM, Ferrari MD (1999) The prevalence and characteristics of migraine in a population-based cohort: the GEM study. Neurology 53:537-542

12. Stang P, Von Korff M, Galer BS (1998) Reduced labor force participation among primary care patients with headache. J Gen Intern Med 13:296-302

13. Boardman HF, Thomas E, Croft PR, Millson DS (2003) Epidemiology of headache in an English district. Cephalalgia 23:129137

14. Nikiforow R, Hokkanen E (1979) Effects of headache on working ability: a survey of an urban and a rural population in Northern Finland. Headache 19:214-218

15. Benassi G, D’Alessandro R, Lenzi PL, Manzaroli D, Baldrati A, Lugaresi E (1986) The economic burden of headache: an epidemiological study in the Republic of San Marino. Headache 26:457-459

16. Rasmussen BK, Jensen R, Olesen J (1992) Impact of headache on sickness absence and utilisation of medical services: a Danish population study. J Epidemiol Commun Health 42:443-446

17. Stovner LJ, Zwart JA, Hagen K, Terwindt G, Pascual J (2006) Epidemiology of headache in Europe. Eur J Neurol 13:333-345

18. Fiane I, Haugland M, Stovner L, Zwart JA, Bovim G, Hagen K (2006) Sick leave is related to frequencies of migraine and non-migrainous headache-the HUNT Study. Cephalalgia 26:960-967

19. Michel P, Dartigues JF, Duru G, Moreau J, Salamon R, Henry P (1999) Incremental absenteeism due to headaches in migraine: results from the Mig-Access French national cohort. Cephalalgia 19:503-510

20. Berg J (2004) Economic evidence in migraine and other headaches: a review. Eur J Health Econom 5:S43-S54

21. Pransky GS, Berndt E, Finkelstein SN, Verma S, Agrawal A (2005) Performance decrements resulting from illness in the workplace: the effect of headaches. J Occup Environ Med 47:34-40

22. Michel P, Auray J, Chicoye A, Dartigues J, Lamure D, Duru G, Henry P, Salamon R (1993) Prise en charge des migraineux en France: Coût et recours aux soins. J Econ Med 11:71-80

23. Auray JP (2006) Impact socio-economique de la migraine et des cephalees en France. CNS Drugs 20(Spec no.1):37-46

24. Neubauer G, Uljaky R (2002) Migraine-a disease and its costs. Pharm Unserer Zeit 31:494-497

25. van Roijen L, Essink-Bot ML, Koopmanschap MA, Michel BC, Rutten FF (1995) Societal perspective on the burden of migraine in The Netherlands. Pharmacoeconomics 7:170-179

26. Lainez MJA, Monzon MJ (2003) The socioeconomic impact of migraine in Spain. In: Reducing the burden of headache. Oxford University Press, Oxford, pp 255-259

27. Björk S, Roos P (1991) Economic aspects of migraine in Sweden. In: Working paper no 8 Institute for Health Economics, Lund. pp 5-24

28. Blau N, Drummond M (1991) Migraine. Office of Health Economics, London, pp 26-30

29. Cull R, Wells N (1992) The economic cost of migraine. Br J Med Econ 2:103-115

30. Berg J, Stovner LJ (2005) Cost of migraine and other headaches in Europe. Eur J Neurol 12(Suppl 1):59-62

31. Rasmussen BK, Jensen R, Olesen J (1992) Impact of headache on sickness absence and utilisation of medical services: a Danish population study. J Epidemiol Commun Health 46:443-446

32. Boardman HF, Thomas E, Croft PR, Millson DS (2003) Epidemiology of headache in an English district. Cephalalgia 23:129-137

33. Badia X, Magaz S, Gutierrez L, Galvan J (2004) The burden of migraine in Spain: beyond direct costs. Pharmacoeconomics 22:591-603
34. Pradalier A, Auray JP, El Hasnaoui A, Alzahouri K, Dartigues JF, Duru G, Henry P, Lanteri-Minet M, Lucas C, Chazot G et al (2004) Economic impact of migraine and other episodic headaches in France: data from the GRIM2000 study. Pharmacoeconomics 22:985-999

35. Elston Lafata J, Moon C, Leotta C, Kolodner K, Poisson L, Lipton RB (2004) The medical care utilization and costs associated with migraine headache. J Gen Intern Med 19:10051012

36. Lucas C, Chaffaut C, Artaz MA, Lantéri-Minet M (2005) FRAMIG 2000: medical and therapeutic management of migraine in France. Cephalalgia 25:267-279

37. Lyngberg AC, Rasmussen BK, Jørgensen T, Jensen R (2005) Secular changes in health care utilization and work absence for migraine and tension-type headache: a population based study. Eur J Epidemiol 20:1007-1014

38. Dueland AN, Leira R, Burke TA, Hillyer EV, Bolge S (2004) The impact of migraine on work, family, and leisure among young women-a multinational study. Curr Med Res Opin 20:15951604

39. Hu XH, Markson LE, Lipton RB, Stewart WF, Berger ML (1999) Burden of migraine in the United States: disability and economic costs. Arch Intern Med 159:813-818

40. Dahlöf CG, Dimenäs E (1995) Migraine patients experience poorer subjective well-being/quality of life even between attacks. Cephalalgia 15:31-36

41. Hamelsky SW, Lipton RB, Stewart WF (2005) An assessment of the burden of migraine using the willingness to pay model. Cephalalgia 25:87-100

42. Morillo LE, Alarcon F, Aranaga N, Aulet S, Chapman E, Conterno L, Estevez E, Garcia-Pedroza F, Garrido J, Macias-Islas M et al (2005) Prevalence of migraine in Latin America. Headache 45:106-117

43. Steiner TJ (2005) Lifting the burden: the global campaign to reduce the burden of headache worldwide. J Headache Pain 6:373-377

44. Leonardi M, Steiner TJ, Scher AT, Lipton RB (2005) The global burden of migraine: measuring disability in headache disorders with WHO's Classification of Functioning, Disability and Health (ICF). J Headache Pain 6:429-440

45. Olesen J, Leonardi M (2003) The burden of brain diseases in Europe. Eur J Neurol 10:471-477

46. Osterhaus JT, Townsend RJ, Gandek B, Ware JE (1994) Measuring the functional status and well-being of patients with migraine headache. Headache 34:337-343

47. Terwindt GM, Ferrari MD, Tijhuis M, Groenen SM, Picavet HS, Launer LJ (2000) The impact of migraine on quality of life in the general population: the GEM study. Neurology 55:624-629

48. Guitera V, Muñoz P, Castillo J, Pascual J (2002) Quality of life in chronic daily headache: a study in a general population. Neurology 58:1062-1065

49. Colás R, Muñoz P, Temprano R, Gómez C, Pascual J (2004) Chronic daily headache with analgesic overuse: epidemiology and impact on quality of life. Neurology 62:1338-1342

50. Lipton RB, Liberman JN, Kolodner KB, Bigal ME, Dowson A, Stewart WF (2003) Migraine headache disability and healthrelated quality-of-life: a population-based case-control study from England. Cephalalgia 23:441-450

51. Bingefors K, Isacson D (2004) Epidemiology, co-morbidity, and impact on health-related quality of life of self-reported headache and musculoskeletal pain-a gender perspective. Eur J Pain 8:435-450

52. Michel P, Dartigues JF, Lindoulsi A, Henry P (1997) Loss of productivity and quality of life in migraine sufferers among French workers: results from the GAZEL cohort. Headache 37:71-78 
53. Lipton RB, Hamelsky SW, Kolodner KB, Steiner TJ, Stewart WF (2000) Migraine, quality of life, and depression: a populationbased case-control study. Neurology 55:629-635

54. Duru G, Auray JP, Gaudin AF, Dartigues JF, Henry P, LantériMinet M, Lucas C, Pradalier A, Chazot G, Hasnaoui AE (2004) Impact of headache on quality of life in a general population survey in France (GRIM2000 Study). Headache 44:571-580

55. Lipton RB, Hamelsky SW, Kolodner KB, Steiner TJ, Stewart WF (2000) Migraine, quality of life, and depression: a populationbased case-control study. Neurology 55:629-635

56. Kececi H, Dener S, Analan E (2003) Co-morbidity of migraine and major depression in the Turkish population. Cephalalgia 23:271-275
57. Zwart JA, Dyb G, Hagen K, Odegard KJ, Dahl AA, Bovim G, Stovner LJ (2003) Depression and anxiety disorders associated with headache frequency. The Nord-Trondelag Health Study. Eur J Neurol 20:147-152

58. Anttila P, Metsahonkala L, Mikkelsson M, Helenius H, Sillanpaa M (2001) Comorbidity of other pains in schoolchildren with migraine or nonmigrainous headache. J Pediatr 138:176-180

59. Hagen K, Einarsen C, Zwart JA, Svebak S, Bovim G (2002) The co-occurrence of headache and musculoskeletal symptoms amongst 51050 adults in Norway. Eur J Neurol 9:527-533

60. Lipton RB, Bigal ME, Kolodner K, Stewart WF, Liberman JN, Steiner TJ (2003) The family impact of migraine: populationbased studies in the USA and UK. Cephalalgia 23:429-440 